
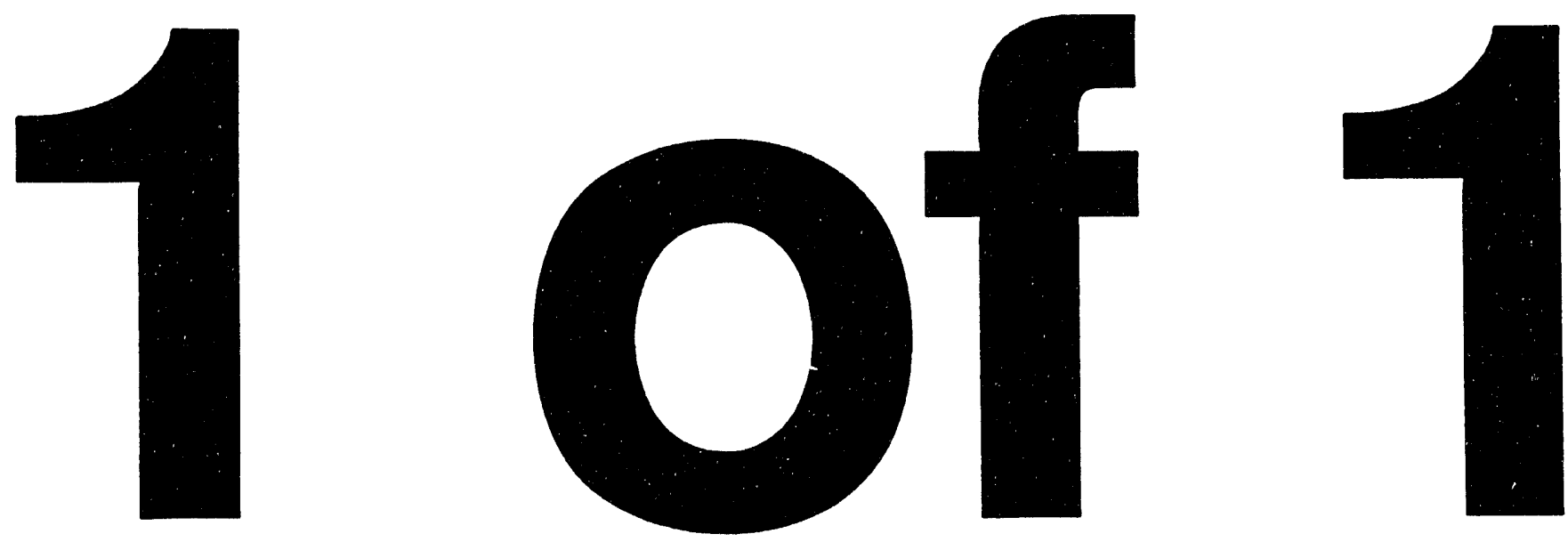
LBL-35056

$\mathrm{UC}-\mathbf{1 6 0 0}$

\section{Meso-Scale Cooling Effects of High Albedo Surfaces: \\ Analysis of Meteorological Data from \\ White Sands National Monument and White Sands Missile Range}

May 20, 1994

Beth Fishman, Haider Taha, and Hashem Akbari

Energy \& Environment Division

Lawrence Berkeley Laboratory

University of California

Berkeley, CA 94720

This work was supported by the U. S. Environmental Protection Agency and by the Assistant Secretary for Energy Efficiency and Renewable Energy, Office of Buildings Technologies of the U. S. Department of Energy under contract No. DE-AC03-76SF00098.

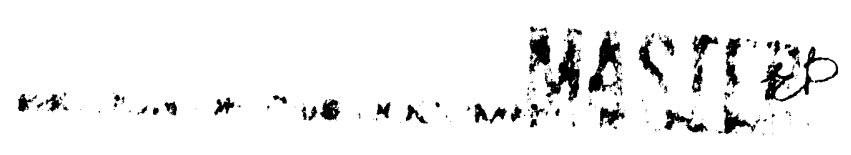




\section{ACKNOWLEDGMENTS}

Meteorological data were supplied by the White Sands Meteorological Team. This assistance is highly appreciated, particularly that of Dennis Eschrich, Joe Ramey, and Terry Jameson. Bill Fuchs assisted the LBL team in measuring the albedo of the dunes area and obtaining further information on the weather stations network at WSMR.

This work was jointly supported by the U.S. Department of Energy and the U.S. Environmental Protection Agency under contract DE-AC0376SF00098. 


\section{ABSTRACT}

Meteorological data from the network of surface weather stations at White Sands Missile Range, NM, were analyzed to determine the mesoscale $(\sim 35 \mathrm{~km}$ by $40 \mathrm{~km})$ impacts of albedo on surface and air temperatures. Measurements were performed in-situ at the White Sands National Monument to characterize the short wave surface albedo and air temperature of the white dunes area. In addition, several measurements of air temperatures within the Monument were made.

In this report, we analyze the impact of albedo on near-surface air temperatures during summer and develop several correlations. We also evaluate the effects of albedo on soil temperature. Our analysis considers the relationship between wind speed, wind direction, and air temperature at White Sands.

Analysis indicates that the high-albedo surface has a measurable impact on the air temperature within the White Sands area compared with air temperatures from the surrounding Missile Range. On average, the White Sands area was $1-2^{\circ} \mathrm{C}$ cooler than its surroundings during daytime hours in August 1992 and June 1993, and was up to $6^{\circ} \mathrm{C}$ cooler at times. This difference in air temperature is attributed mainly to differences in albedo; the dunes have an average measured albedo of 0.60 , whereas the surrounding desert areas have an average albedo of 0.20 0.25 . On average, the soil (measured at $\sim 1 \mathrm{~cm}$ below surface) was on the average $5^{\circ} \mathrm{C}$ cooler than that of the surrounding darker area, $15^{\circ} \mathrm{C}$ cooler at times. No direct correlation between soil temperatures and air temperatures could be established with the available data. 


\section{INTRODUCTION}

Urban summer daytime temperatures often exceed those of the surrounding rural areas. Summer "urban heat islands" are caused by dark roofs and paved surfaces as well as the lack of vegetation (Oke, 1982). Researchers at Lawrence Berkeley Laboratory are interested in studying the effects of increasing the albedo of roof tops and paved surfaces in order to reduce the impacts of summer urban heat islands. Increasing the albedo of urban surfaces may reduce this heat island effect in two ways, directly and indirectly.

The direct effect involves reducing surface temperature and, therefore, heat conduction through the building envelope. This effect of surface albedo on surface temperatures is better understood and has been quantified in several studies (Akbari, et al, 1993). The indirect effect is the impact of high albedo surfaces on the near surface air temperatures. Although the indirect effect has been modeled for the Los Angeles basin by Sailor (1993), direct field observations are required. The objective of this report is to investigate the meso-scale climate of a large high albedo area and identify the effects of albedo on the near surface air temperature. To accomplish this task, data from several surface weather stations at White Sands, New Mexico were analyzed.

This report is organized into six sections in addition to this introduction. The first gives the general geological, topographic, and meteorological background of White Sands. The second is a discussion of the basic surface meteorology of the White Sands region. This section is followed by a general discussion of the instrumentation and available data. The fourth section is a description of the method used for data analysis. The fifth section which presents the results of this analysis. Finally, the last section is the summary and conclusion, where a discussion of the results is presented.

\section{BACKGROUND}

The White Sands National Monument and its setting within the White Sands Missile Range can provide an opportunity to verify and quantify the large-scale imf.acts of albedo variation on air temperature in the lowest few meters of the atmosphere. The soil at White Sands 
is highly reflective and is composed of gypsum (hydrous calcium sulfate). White Sands is located in the western part of the Tularosa Valley at the foot hills of the San Andreas mountains. The area, shown in Figure 1, is approximately $30 \times 45 \mathrm{~km}$ and bounded on the east by the Sacramento mountains. White Sands is divided into two different regions: the western half is a gypsum flat, and the eastern half is mostly sand dunes. ${ }^{1}$

During the summer, tropical storm fronts arrive at White Sands from the south, creating prevailing southerly winds and frequent thunderstorms. Average summer air temperature, measured at $1.5 \mathrm{~m}$, for the valley is $-27^{\circ} \mathrm{C}$ with maximum temperatures as high as $40^{\circ} \mathrm{C}$. Monthly summer average precipitation for the entire range varies from $2.5-12.7 \mathrm{~cm}$. Besides precipitation, and ground water, Lake Lucero at the south east end of the gypsum flat is the only known source of water. However, the water table is frequently at the surface on the gypsum flats. Average relative humidity at $1.5 \mathrm{~m}$ was $\sim 30 \%$ for June 1993, and $\sim 45 \%$ for August 1992 .

\section{BASIC SURFACE METEOROLOGY}

Surface temperature is determined by albedo and solar radiation, long wave radiative fluxes, and sensible and latent heat fluxes (which are in part determined by horizontal wind speed) (Oke, 1987). A higher albedo signifies that less short wave radiation will be absorbed by the surface, resulting in lower surface temperatures. In general, high albedo surfaces have lower surface temperatures than low albedo surfaces with equivalent surface roughness and geometry under similar atmospheric conditions (Taha, et al 1992).

Through the processes of heat conduction and convection, air temperature within the lowest few meters of the atmosphere is determined in part by the surface temperature. It is

1 The gypsum flats were once covered by Lake Otero. The gypsum deposit was created by ancient rains which washed away gypsum from exposed sedimentary rocks. This soluble gypsum entered the ground water table and filled the bed of Lake Otero. The lake has since dried up, leaving behind the present dry gypsum flats. The dunes were created as prevailing westerly winds swept particles from the dry lake bed's gypsum deposits. At the south end of White Sands is a small lake, Lake Lucero, which is the remains of Lake Otero (Dodge, 1971). 
hypothesized that lower surface and air temperatures will be observed directly over White Sands because of its high aibedo. Surface temperature is directly linked to solar radiation and albedo, however, air temperature is indirectly linked to surface temperature. Therefore, we expect to see smaller differences due to albedo in air temperature than in surface temperature. This has been observed by Oke, et al. (1989) in a comparison of satellite derived surface temperature and measured near surface air temperatures in several west coast summer urban heat islands.

The vertical temperature profile changes during the day as solar radiation and surface temperature increase (Oke, 1987). As the surface heats up, an unstable lapse rate arises and convective vertical mixing takes place. This is in contrast to evening temperature profiles which in general are stable. We expect that afternoon instability and vertical mixing will dampen the effects of the surface temperature and albedo on air temperature. However stable nighttime inversions may persist into the late morning. By limiting convective mixing, this inversion layer will accentuate the coupling of air and surface temperatures. If this mechanism exists it will be apparent in the diurnal pattern of air temperature depression over White Sands.

Horizontal wind speed may affect air temperature in several ways. Faster wind speeds enhance convection and thus the amount of heat transferred from the surface to the air (Chapman, 1987). In the limiting case, at very high wind speeds, we expect surface and air temperatures to approach each other, and temperature difference over White Sands to approach zero. Faster wind speeds may increase the flux of advective heat over White Sands, allowing less time for the incoming warmer air to equilibrate with the cooler surface temperatures. However, due to the nature of turbulence and heat transfer, this cannot be determined from our data.

Areas adjacent to White Sands may be affected by the high albedo surface in two ways. First, synoptic winds crossing from White Sands may bring cooler air into the surrounding area. Second, any temperature depression at White Sands it will result in a pressure gradient between the air over White Sands and the surrounding air . This pressure gradient will result in localized subsidence and divergence centered on the high-albedo area of White Sands. Warmer air from 
the surrounding desert, which is less dense than the colder air at White Sands, may create a convective cell. This would occur if the warmer air was moving towards White Sands and forced above it due to the density differential. This air would then displace ambient air in the upper boundary layer which would subside over White Sands, creating a radial wind, and carrying the cooler air to weather stations just outside the high-albedo region. If either mechanism exists, it would be most apparent in the relationship between wind direction and air temperature depression at White Sands.

\section{INSTRUMENTATION AND MEASUREMENTS}

Figure 1 shows the locations of 9 White Sands Missile Range (WSMR) Meteorological Team surface weather stations with single or multi-level sensors. We examined data from 1-m high sensors in the flat area within and surrounding White Sands. We chose these stations because their relative elevations are within $30 \mathrm{~m}$, and all are within close proximity to the high albedo area. Northrup Strip and Ratscat are the only stations within White Sands, and both are on the gypsum flats. At this time we have no weather data from the dunes.

Hourly meteorological data consist of air, dew point, and soil temperatures, and relative humidity measured at the 1.5 meter level; air temperature differences between different atmospheric levels for those stations that have sensors at 1 and 5 meters; local static pressure, sea level pressure, and altimeter setting, vector wind direction and wind speed, (the hourly average of 15 minute samples), and hourly maxima; and total horizontal solar radiation and precipitation. August 1992 data include soil temperatures measured $1 \mathrm{~cm}$ below the surface with a thermistor from Campbell Scientific. Air and soil temperatures are accurate up within $0.1^{\circ} \mathrm{C}$. Relative humidity is accurate within $1 \%$. Wind data is accurate above a threshold of $1 \mathrm{~m} / \mathrm{s}$ and within 0.5 $\mathrm{m} / \mathrm{s}$ and $1^{\circ}$. Data was chosen for August of 1992 because it was unusually dry for this time of year and it was the peak of the solar cycle. June 1993 data, which was before the summer 
* ABC Sito

* Denver Witt

* Jallon

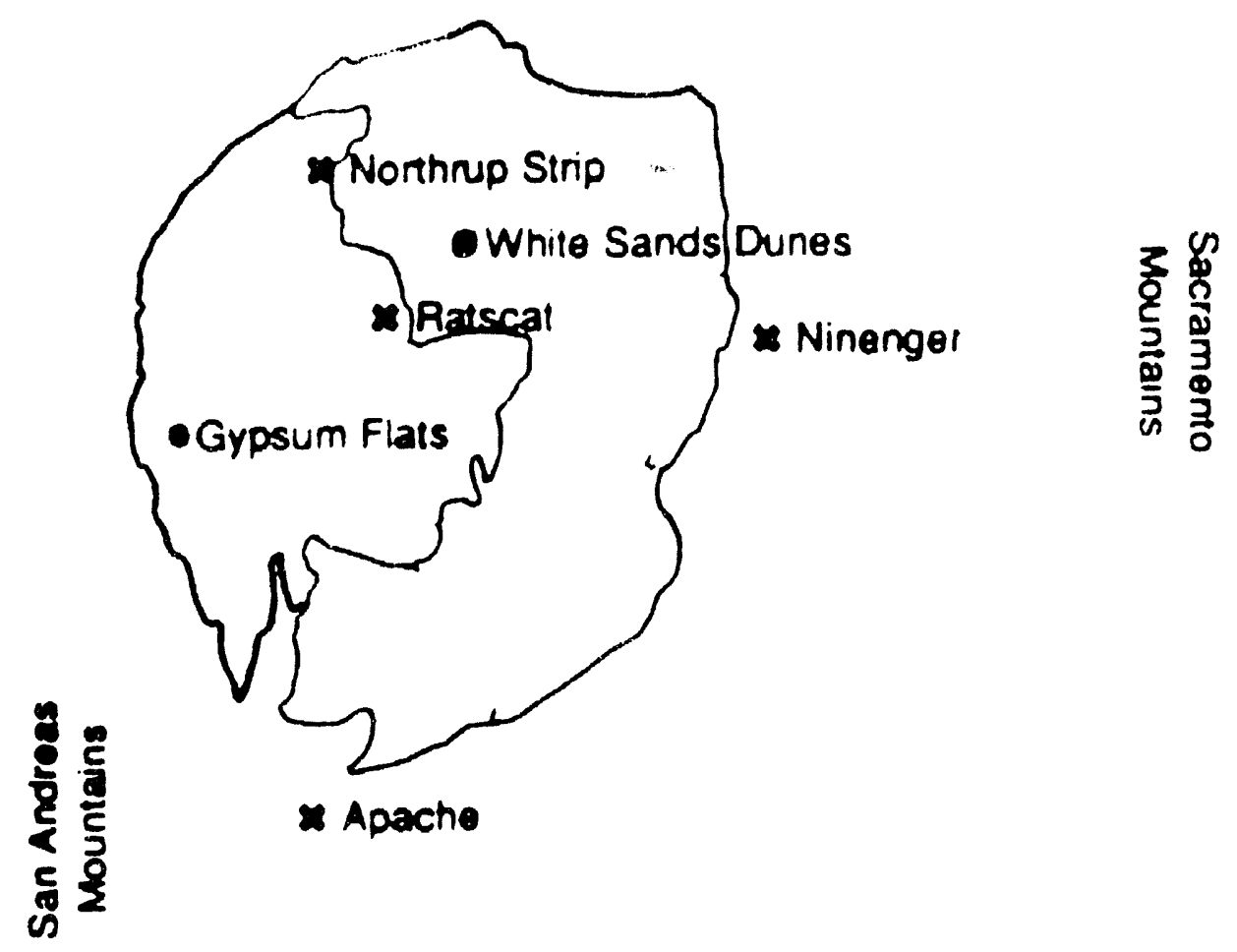

* Greg Siro

2.Station

L

\lrcorner 


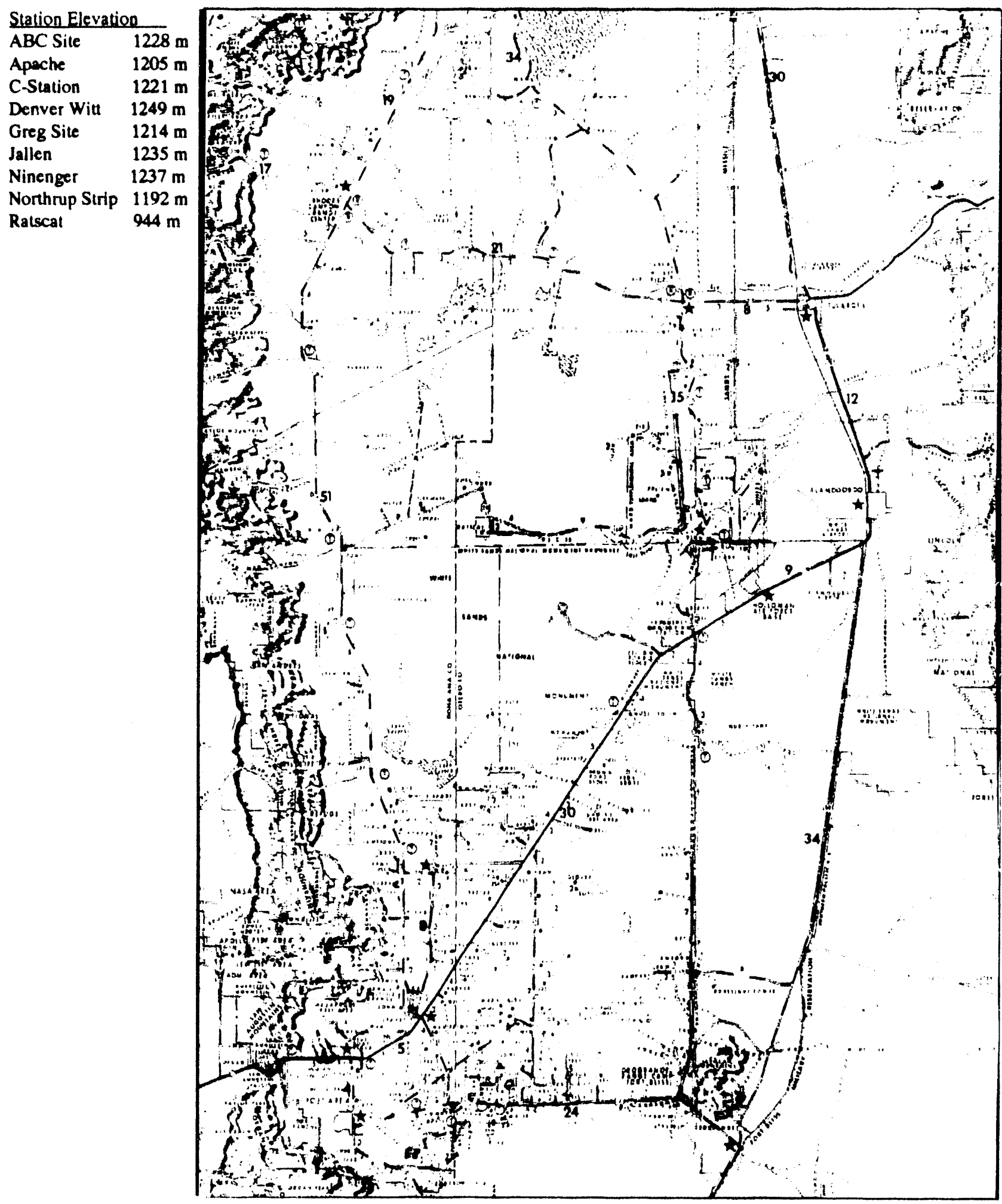

Figure 1. Locations of 9 weather stations used in our analysis. Note that Northrup Strip and Ratscat are the only stations located within the White Sands Area, and are located within the gypsum flats. Ninenger and Apache are located to the east and south respectively and are the closest stations to White Sands. Two mountain ranges surround White Sands: the San Andreas to the east and the Sacramento to the west. White Sands is divided into two main areas: the gypsum flats are to the west and have an average albedo of $(0.50$, the duncs are to the east and have an average albedo of 0.60 . 
monsoon, was added to supplement this data after we identified that soil moisture influences the August data. June 1993 data include neither soil temperature nor vertical temperature difference.

White Sands Meteorological Team calibrates their instruments on a quarterly basis and keeps records when a device is yielding suspicious output. When this occurs, technicians are sent to repair or replace the device. Between the summer of 1992 and 1993, no suspicious output was reported, except at Greg Site (see figure 1). Apparently the temperature could not be calibrated and the thermistors were replaced.

The solar albedo was measured using an Eppley Precision Spectral Pyranometer following a method devised by Taha (1993). In this method, the device is placed both face up and face down on a long pole two feet of the ground. The two measurements are then compared to determine the albedo. Several spot measurements were performed in the Monument area over the dunes as well as the flat surrounding areas on October 17, 1992 at about solar noon. Conditions during measurement were clear, and relatively low wind speeds (estimated $1.5 \mathrm{~m} \mathrm{~s}^{-1}$ ). Similar measurements were also performed using a Licor Silicon pyranometer, during clear conditions at approximately noon on July 14 and 15, 1993. These measurements agree with high altitude aircraft and laboratory measurements of albedo which were performed for satellite calibration by the National Environmental Satellite Data and Information Service (Smith, Levin, and Knoll, 1985), and with laboratory measurements made by Walraven and Coulson, (1972). Table 1 shows the results of these measurements.

\section{DATA ANALYSIS AND METHOD}

The summer season is generally characterized by monsoons and frequent afternoon thunder showers. Given that surface moisture may introduce a strong bias in studying the impacts of surface albedo on air and soil temperatures, days when precipitation occurred were removed from the data set. After removing rainy days from the data set we were left with 12 days for both August 1992 and June 1993. We cannot be sure this exclusion will remove all days when surface moisture was present. For example, after an evening thunderstorm on July 12 , 1993, we observed large pools of water within the gypsum flats area. These pools remained for 
several days. This would imply the bias introduced by rain and surface moisture extends for at least a day after a rain fall. However, given the small amount of data, we cannot remove the days following a rain day.

C-Station was selected as a control station, as it was assumed to be representative of the desert area of the greater WSMR basin. C-Station (No. 1) is at the southern end of WSMR, and approximately $50 \mathrm{~km}$ upwind of the dunes area. It is located on a desert soil with sparse vegetation. There are no other apparent factors, such as bodies of water or peculiar topography, affecting the micro-climate at this location.. The air temperature depression $\left(\Delta \mathrm{T}_{\mathrm{a}}\right)$, defined here as the difference in air temperature between C-Station and the station of interest, was examined as a function of wind speed, wind direction, and time of day. Histograms were generated in order to identify basic wind circulation patterns. Solar radiation and soil temperature were also analyzed to understand the complete effect of albedo on micro climate.

Time series plots of air temperature and dew point were examined at all stations to investigate any possible biases or lack of calibration between station apparaius. Outliers were defined as any extreme fluctuation or value which could not be explained given our present understanding of the local climate and basic meteorological principles. We have only removed those which were clearly due to data collection errors or instrument malfunction.

\section{RESULTS}

\subsection{Albedo Measurements}

Table 1 lists the various results for albedo measure at White Sands. These measurements are lower than measurements made of dry sand in the laboratory, but correlate well with those made for wet gypsum sand (Walraven and Coulson, 1972). Measured albedo values at the dunes are approximately $0.63 \pm 0.05$, and at the gypsum flats, measured albedo ranged between 0.45 and 0.55 (average albedo from 5 observations is 0.51 ). Thus the effective albedo of the dunes area in the White Sands National Monument was approximately 0.60 (area weighted average). Heterogeneous transition areas were found to extend for miles outside the dunes areas and have 
albedos ranging from 0.29 to 0.53 . Inter-dune areas were frequently vegetated and covered by dark blue-green algae resulting in a lower albedo of $\sim 0.41$. By contrast, the albedo of the surrounding desert areas was 0.18-0.25.

Table 1. Albedo measurements taken at different times with different devices

\begin{tabular}{|ccc|}
\hline Surface Type & $\begin{array}{c}\text { October 17 1992 } \\
\text { Epply Pyranometer } \\
0.28-2.8 \mu \mathrm{m} \text { range }\end{array}$ & $\begin{array}{c}\text { July 14 and 15 1993 } \\
\text { Licor Pyranometer } \\
0.28-2.8 \mu \mathrm{m} \text { range }\end{array}$ \\
\hline Dunes & 0.64 & 0.63 \\
Gypsum Flats & 0.55 & 0.51 \\
\hline $\begin{array}{c}\text { Area Weighted } \\
\text { Average }\end{array}$ & 0.61 & 0.58 \\
\hline C-Station & 0.20 & 0.24 \\
\hline
\end{tabular}

\subsection{Air Temperature Depression}

Table 2 shows daytime average temperatures for the ten stations shown in Figure 1. Northrup Strip and Ratscat stations clearly show temperature depressions for both August 1/92 and June 1993. Note that temperature differences in June are less than those in August. This difference may be due to moisture effects. The average daily peak difference is defined as the maximum air temperature at $\mathrm{C}$-Station minus the maximum air temperature at the station of interest. In general, these maxima occur at the same hour, between 1:00 and 3:00 p.m. Mountain Standard Time. The average daily maximum $\Delta \mathrm{T}_{\mathrm{a}}$ was found to be greater than the average daily peak difference. This is due to the fact that maximum $\Delta T_{a}$ does not occur in the afternoon hours, but in the morning, as shown in Figure 2. Ratscat and Northrup Strip, stations within White Sands, are the only stations which show significant values of $\Delta T_{a}$. This implies that there are little or no temperature effects extending outside the high albedo area.

All nighttime temperatures corresponding to data used for Table 2 are within the range of equipment error $\left(0.1^{\circ} \mathrm{C}\right)$ of each other. This implies that the statistics in the table are not a result of instrument error, or lack of calibration. This can be seen in Figure 2, where nighttime 
$\Delta \mathrm{T}_{\mathrm{a}}$ approach zero for the four stations shown. As stated above, White Sands Meteorological Team calibrates their instruments on a quarterly basis and keeps records when a device is yielding suspicious output. Records indicate that Greg site was $0.6{ }^{\circ} \mathrm{C}$ off from the calibration psycrometer in January of 1992. This may explain why Greg Site has a positive $\Delta T_{a}$ in 1992 and a negligible $\Delta \mathrm{T}_{\mathrm{a}}$ in 1993 . The device was replaced before June of 1993 , making any comparison between the two years of data useless. As far as we know, no other devices were replaced between the summer of 1992 and 1993. 
Table 2 Temperature Depression Statistics for Several Stations at White Sands Missile Range. a) August 1992 and b) June 1993.

Averages are taken over (12-14) daytime hours only when solar radiation is greater than to zero. All rain days are excluded. Number of observations: 156

a)

\begin{tabular}{|c|c|c|c|c|c|c|}
\hline $\begin{array}{c}\text { Station } \\
\text { Name }\end{array}$ & $\begin{array}{l}\text { Average } \\
\text { Air Temp } \\
\text { (C) }\end{array}$ & $\begin{array}{c}\text { Average } \\
\Delta T_{\mathbf{a}} \\
\left(T_{\text {cst }}-T_{\text {air }}\right)\left({ }^{\circ} \mathrm{C}\right)\end{array}$ & $\begin{array}{c}\text { Standard } \\
\text { deviation } \\
\sigma(\mathrm{C})\end{array}$ & $\begin{array}{l}\text { Maximum } \\
\qquad \mathrm{T}_{\mathrm{a}} \\
\left({ }^{\circ} \mathrm{C}\right)\end{array}$ & $\begin{array}{l}\text { Average daily peak } \\
\text { difference } \\
{\text { (maxT } T_{\text {cst-maxT }} \text { air) }}_{\text {(C) }}\end{array}$ & $\begin{array}{c}\begin{array}{c}\text { Average } \\
\text { daily } \\
\text { maximum }\end{array} \\
\Delta \mathrm{T}_{\mathrm{a}}\left({ }^{\circ} \mathrm{C}\right)\end{array}$ \\
\hline Abc Site & 29.13 & 1.06 & 1.22 & 5.00 & 1.67 & 3.08 \\
\hline Apache & 29.70 & 0.48 & 1.56 & 8.34 & 0.68 & 2.91 \\
\hline C-Station & 30.18 & --.---.--- & --.----.- & ------. & - & 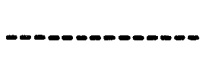 \\
\hline $\begin{array}{c}\text { Denver } \\
\text { Witt }\end{array}$ & 29.70 & 0.48 & 1.38 & 4.45 & 0.42 & 2.65 \\
\hline Greg Site & 28.63 & $1.55 \dagger$ & 1.08 & 5.00 & 2.22 & 3.12 \\
\hline Jallen & 29.10 & 1.08 & 1.32 & 6.12 & 1.41 & 3.12 \\
\hline Ninenger & 29.57 & 0.62 & 1.4 & 8.34 & 0.77 & 2.91 \\
\hline $\begin{array}{l}\text { Northrup } \\
\text { Strip }\end{array}$ & 28.49 & 1.69 & 1.54 & 5.56 & 2.01 & 3.98 \\
\hline Ratscat & 28.15 & 2.04 & 1.60 & 6.67 & 2.22 & 4.32 \\
\hline
\end{tabular}

b)

\begin{tabular}{|c|c|c|c|c|c|c|}
\hline $\begin{array}{c}\text { Station } \\
\text { Name }\end{array}$ & $\begin{array}{l}\text { Average } \\
\text { Air Temp } \\
\text { (C) }\end{array}$ & $\begin{array}{c}\text { Average } \\
\Delta \mathrm{T}_{\mathbf{a}} \\
\left(\mathrm{T}_{\text {cst }}-\mathrm{T}_{\text {air }}\right)(\mathrm{C})\end{array}$ & $\begin{array}{c}\text { Standard } \\
\text { deviation } \\
\sigma(\mathrm{C})\end{array}$ & $\begin{array}{l}\text { Maximum } \\
\qquad \mathrm{T}_{\mathrm{a}} \\
(\mathrm{C})\end{array}$ & $\begin{array}{l}\text { Average daily peak } \\
\text { difference } \\
\text { (maxTcst-maxTair) } \\
\text { (C) }\end{array}$ & $\begin{array}{c}\begin{array}{c}\text { Average } \\
\text { daily } \\
\text { maximum }\end{array} \\
\Delta \mathrm{T}_{\mathrm{a}}\left({ }^{\circ} \mathrm{C}\right)\end{array}$ \\
\hline Abc Site & 31.67 & 0.20 & 1.10 & 5.00 & 0.10 & 2.27 \\
\hline Apache & 32.45 & -0.58 & 1.12 & 6.12 & -1.31 & 1.67 \\
\hline C-Station & 31.87 & - & ------- & ------- & 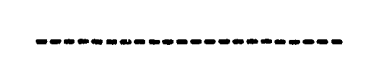 & 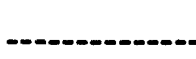 \\
\hline $\begin{array}{c}\text { Denver } \\
\text { Witt }\end{array}$ & 32.13 & -0.26 & 1.17 & 3.89 & -0.40 & 1.92 \\
\hline Greg Site & 32.19 & -0.31 & 0.64 & 3.34 & -0.61 & 0.96 \\
\hline Jallen & 31.76 & 0.10 & 1.15 & 3.89 & 0.05 & 1.92 \\
\hline Ninenger & 31.89 & -0.14 & 1.27 & 6.12 & -.038 & 2.17 \\
\hline $\begin{array}{l}\text { Northrup } \\
\text { Strip }\end{array}$ & 30.35 & 1.53 & 1.30 & 5.00 & 1.37 & 3.49 \\
\hline Ratscat * & 30.56 & 1.32 & 1.46 & 6.12 & 0.96 & 3.54 \\
\hline
\end{tabular}

* These Stations are within White Sands Gypsum Flats area albedo $\sim 0.50$.

$\dagger$ This number is an anomaly which is probably due to instrument error. Greg Site is within close proximity to C-Station and should not show any significant temperature depression. 
Based on the results presented in Table 2, four stations were selected for more detailed analysis. These station all are within or directly adjacent to White Sands, and all show some temperature depression. Figure 2 shows several plots of $\Delta \mathrm{T}_{\mathrm{a}}$ averaged by hour for Ratscat and Northrup Strip, Ninenger and Apache stations. These averages are computed for non-rainy days only. For stations within White Sands, $\Delta \mathrm{T}_{\mathrm{a}}$ reaches its maximum value in the morning. In the early morning atmospheric conditions are usually stable and vertical mixing is negligible. At this time advection below this inversion layer is not significant. Thus, near surface air temperature is a strong function of the station surface temperature. In the afternoon, as surface temperatures become hotter, the lower atmosphere becomes unstable. Vertical mixing dampens the direct effects of surface temperature on $\Delta T_{\mathrm{a}}$. The effect of vertical mixing is more apparent during June than in August, where average $\Delta T_{a}$ falls off rapidly as solar noon approaches.

Figures 2.C and 2.D are consistent with the results of Table 2. Figures 2.C and 2.D demonstrate that temperature depression for stations outside of White Sands is not significant during the daytime when we would expect to see an albedo effect. At Apache and Ninenger $\Delta T_{a}$ fluctuates due to mechanisms which we cannot explain. During the day $\Delta \mathrm{T}_{\mathrm{a}}$ is between $\pm 1{ }^{\circ} \mathrm{C}$. Ninenger was observed to have a lower albedo than C-Station and is not directly downwind of either White Sands or C-Station. A greater incidence of easterly winds from the dunes area in August of 1992 may account for the $1^{\circ} \mathrm{C}$ difference between June and August peak $\Delta \mathrm{T}_{\mathrm{a}}$. August 1992 also has a higher incidence of northerly daytime winds at Apache. Apache is directly to the south of White Sands, and therefore may be measuring cooler air coming directly from the high albedo area. However, differences between this data for June and August implies that there is no constant relationship between air temperatures at these stations and at C-Station. 
Figure 2.a.: Ratscat. $\Delta \mathrm{T}_{\mathrm{a}}$ averaged by hour for June 1993 and August 1992 . Rainy days have been omitted. Vertical mixing may be a stronger factor in June than August. Peak $\Delta T_{a}$ occurs one hour later in August than June. Solar noon is at 1300 Mountain Standard Time. Lines represent 1 standard deviation from the mean.
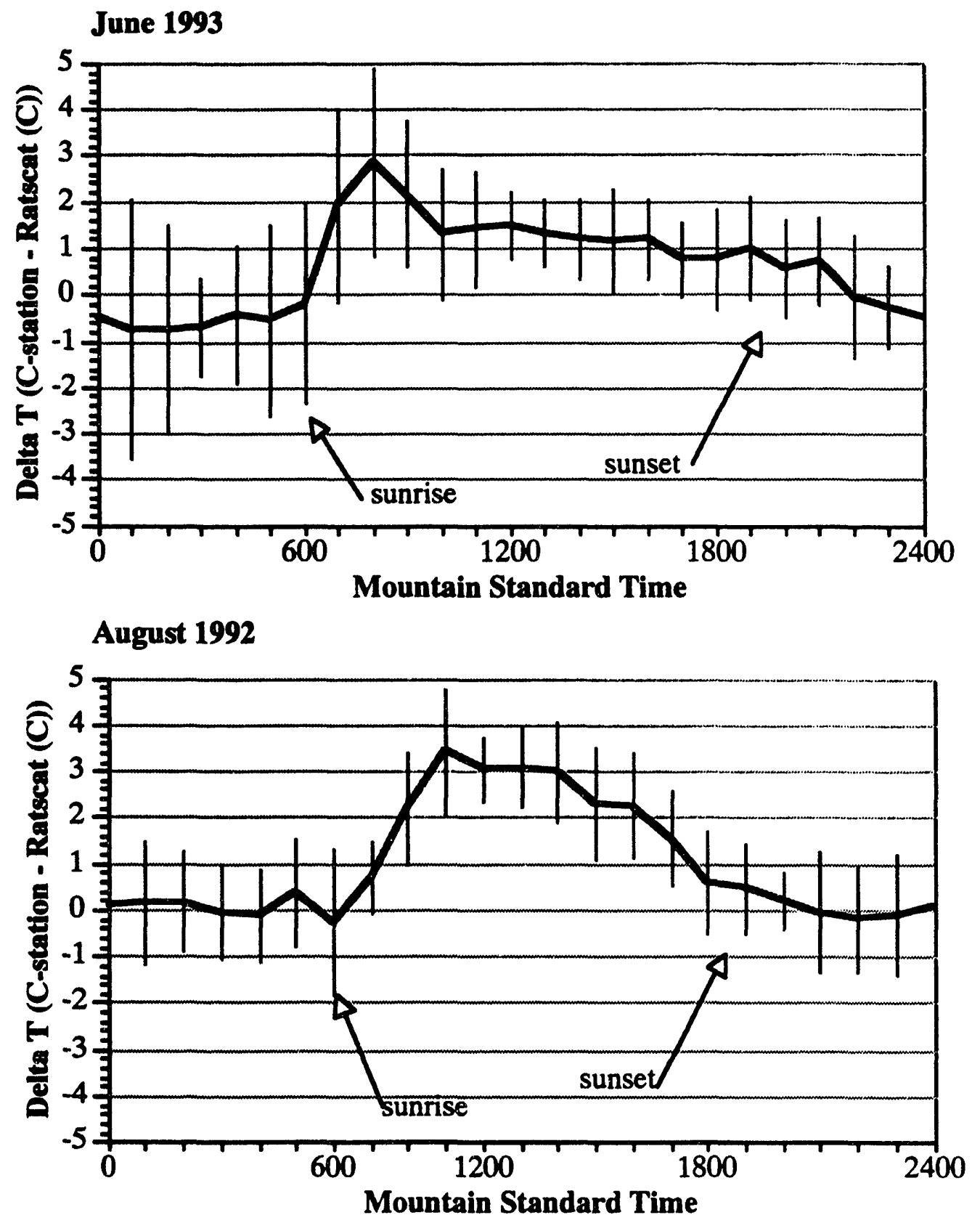
Figure 2.b.: Northrup Strip. $\Delta \mathrm{T}_{\mathrm{a}}$ averaged by hour for June 1993 and August 1992 at Northrup Strip. Rainy days have been omitted. Lines represent one standard deviation from the mean. Solar noon is at 1300 Mountain Standard Time.
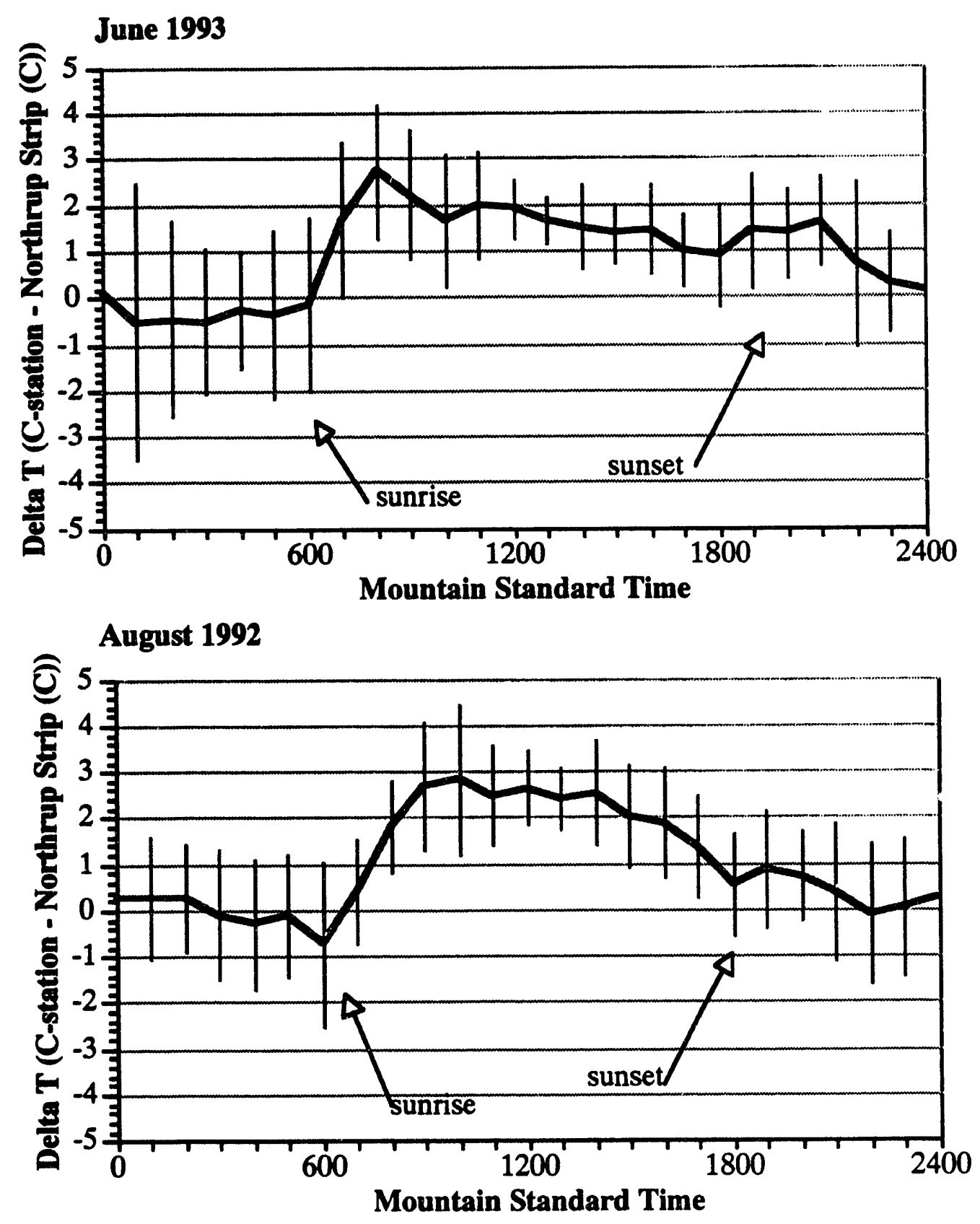
Figure 2.c.: Ninenger. $\Delta \mathrm{T}_{\mathrm{a}}$ averaged by hour for June 1993 and August 1992 at Ninenger station. Rainy days have been omitted. Lines represent one standard deviation from the mean. Solar noon is at 1300 Mountain Standard Time.
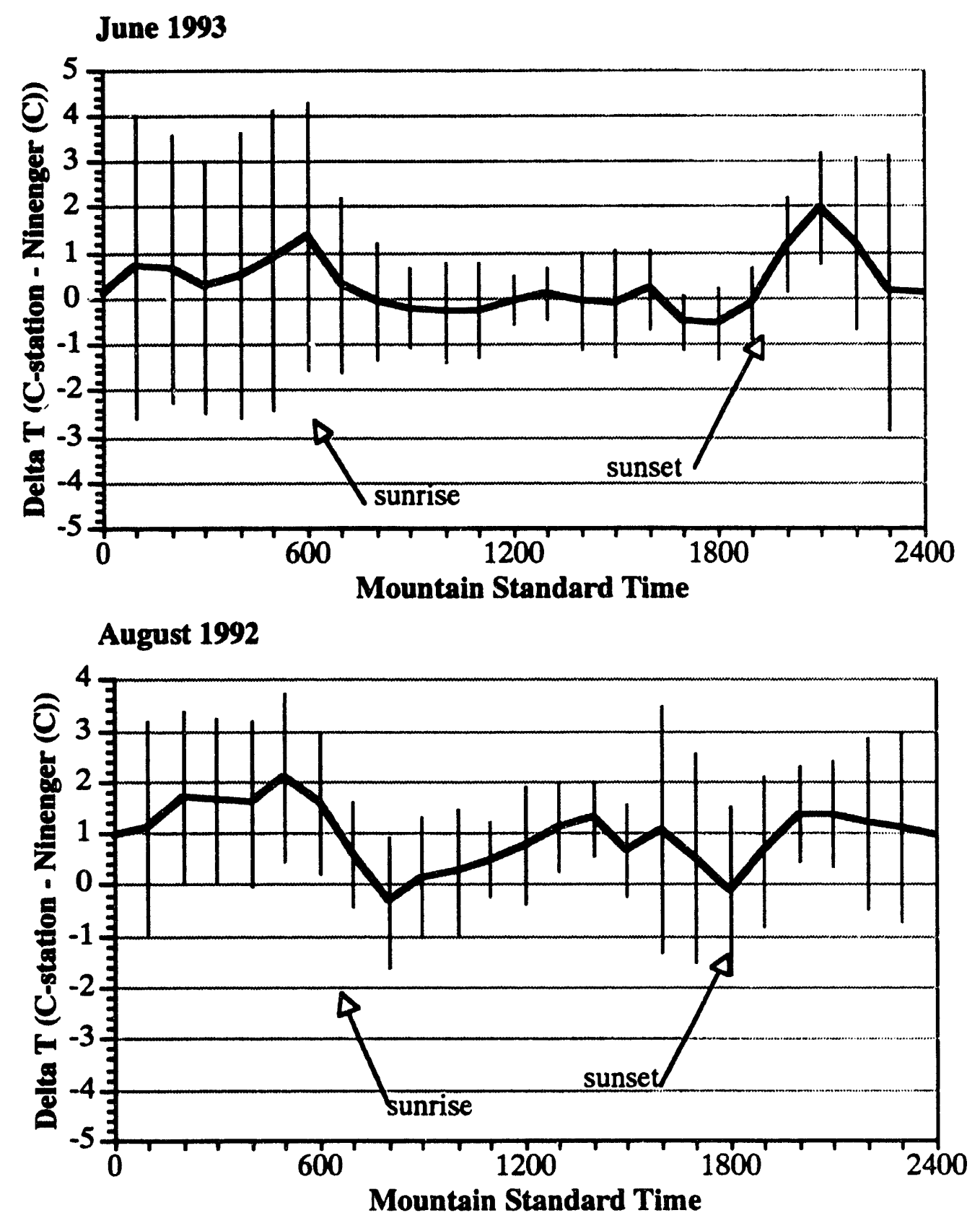
Figure 2.d.: Apache. $\Delta \mathrm{T}_{\mathrm{a}}$ averaged by hour for June 1993 and August 1992 at Apache station. Rainy days have been omitted. Lines represent 1 standard deviation from the mean. Solar noon is at 1300 Mountain Standard Time.
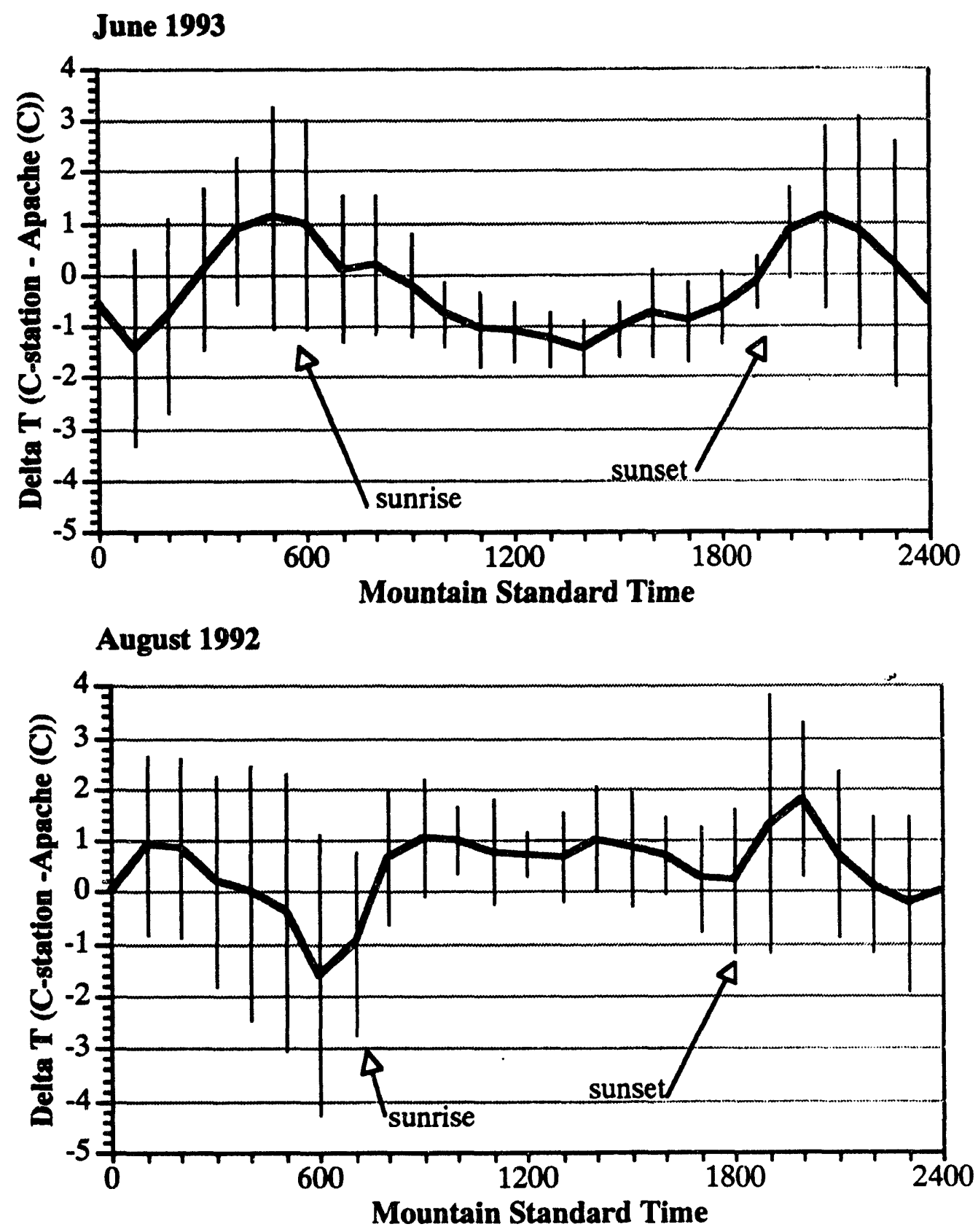


\subsection{Wind Speed, Wind Direction and $\Delta T_{a}$}

We attempted to examine the relationship between temperature depression, $\Delta T_{a}$, and wind speed. However, our efforts were restricted by the fact that we cannot identify any direct correlation between wind speeds at C-Station and Ratscat station. On average, wind speeds at Ratscat are faster than those at C-Station. This difference may be caused by topography. CStation is closer to the edge of the San Andreas mountain range, and directly north of the Organ mountains which run East-West. Therefore it may be sheltered from meso-scale synoptic winds. Further analysis of the effect of wind speed on air and soil temperatures proved inconclusive due to the time lag and lack of correlation between station air and soil temperatures. At this time our analysis of wind speed on temperature depression is inconclusive.

Figure 3 demonstrates a slight correlation between wind direction and $\Delta \mathrm{T}_{\mathrm{a}}$ at Apache, as well as at other stations. This figure depicts $\Delta \mathrm{T}_{\mathrm{a}}$ as a function of wind direction. Shaded areas mark the direction of the dunes, gypsum flats, and the darker surrounding desert. The radial axis represents the magnitude of $\Delta T_{a}$ which corresponds to the wind direction vector. Wind vectors are pointing towards the station of interest, which is located at the origin of the graph. $\Delta T_{a}$ is not a strong function of wind direction at Ratscat and Northrup strip because these stations are surrounded by White Sands. As mentioned above, Apache and Ninenger are adjacent to the high albedo area. When wind is coming directly from White Sands, there is some evidence of cooler air temperatures. There are also anomalous cases where higher values of $\Delta T_{a}$ correspond to directions opposite of the dunes. These outliers may be explained by topography. For example, the incidence of high $\Delta T_{a}$ moving west towards Ninenger may be caused by cool air coming directly from the Sacramento mountains to the east.

Figure 3 also shows that there is higher incidence of winds coming from the White Sands than there are moving towards White Sands. This suggests that there may be a circulation effect generated by the air temperature depression over the dunes area. Warmer air rising over the desert adjacent to White Sands, would be forced to flow over the high pressure air mass directly above White Sands. This air might then displace ambient air aloft, which would in turn push 
cooler air outwards from the high albedo area. The end result of the pressure gradient between warmer and cooler air masses is a radial wind moving outwards from White Sands. However, more carefully designed experiments would be necessary to determine if such a circulation effect exists.

\subsection{Soil temperature}

We restricted our analysis of soil temperatures to stations that monitor high albedo sand. As with our analysis of air temperature, C-Station is used as a control. Of all the stations used in this study only Ratscat and Northrup Strip show significant deviation in soil temperature from CStation.

Soil temperature data at $1-2 \mathrm{~cm}$ in depth is available only for August 1992. Daytime average soil temperatures at Ratscat are $\sim 5^{\circ} \mathrm{C}$ cooler than those at C-Station, while 24 hour averages are $3.4^{\circ} \mathrm{C}$ lower. These statistics are summarized in Table 3 below. Northrup Strip soil temperatures are cooler than those of Ratscat. This may have been caused by excess surface moisture at Northrup, or the station's proximity to the dunes (Northrup Strip is surrounded by more dunes area than Ratscat.) However, Ratscat has a higher average relative humidity for the month of August than Northrup Strip. Figure 4 shows $\Delta T_{S}$ (difference in soil temperature between C-Station and station of interest) averaged by hour. Note that the peak difference is in the afternoon, when soil temperatures are reaching their peak. The figure shows that at Ratscat, $\Delta T_{s}$ returns to zero during the evening, indicating that the existence of $\Delta T_{s}$ is a daytime effect and thus a direct result of albedo, rather than a bias in the soil temperature probe.

Like albedo, soil moisture, is a dominant contributing variable to soil temperature $\left(\mathrm{T}_{s}\right)$. We do not have at this time any data on soil moisture. Researchers at University of Texas at Austin are currently studying the water table at White Sands and it's effect on aeolian transport. They report the water table is generally lower within the dunes, but can fluctuate wildly between the surface and $90 \mathrm{~cm}$ in depth on the gypsum flats. The NOAA/ NESDIS mission also measured soil moisture between the dunes and the gypsum flats(Smith, 1984). They have found that the 
dunes are dry compared with the flats in the summer season. The average White Sands soil moisture was found to be between 10 and $15 \%$ in June of 1981 , but less than $0.5 \%$ in August 1982. Excess soil moisture not only effects soil temperature via evaporation, it lowers the albedo of the soil and increases the absorbed incident radiation (Walraven \& Coulson, 1972). Unfortunately, other than these sources, we have no direct data on soil moisture. From this information we can assume that soil moisture has a greater effect on soil temperature at the flats more than the dunes. 
Figure 3a. Wind direction Frequency vs. $\Delta \mathrm{T}_{\mathrm{a}}$, Ninenger, Ratscat, Northrup Strip and Apache. August 1992. Plot is for non-rainy day time hourly data only. Directional axis represents wind direction vector. Vectors are pointing towards origin, which represents station location. As with a traditional wind rose, the length of the vector represents the frequency of occurrence for each wind direction. Width of each vector represents the magnitude of $\Delta T_{a}$. In this case the wind direction has been classified into 8 groups of $45^{\circ}$ each starting with $0^{\circ} \Delta \mathrm{T}_{\mathrm{a}}$ has been scaled into 4 groups as described in the legend below.

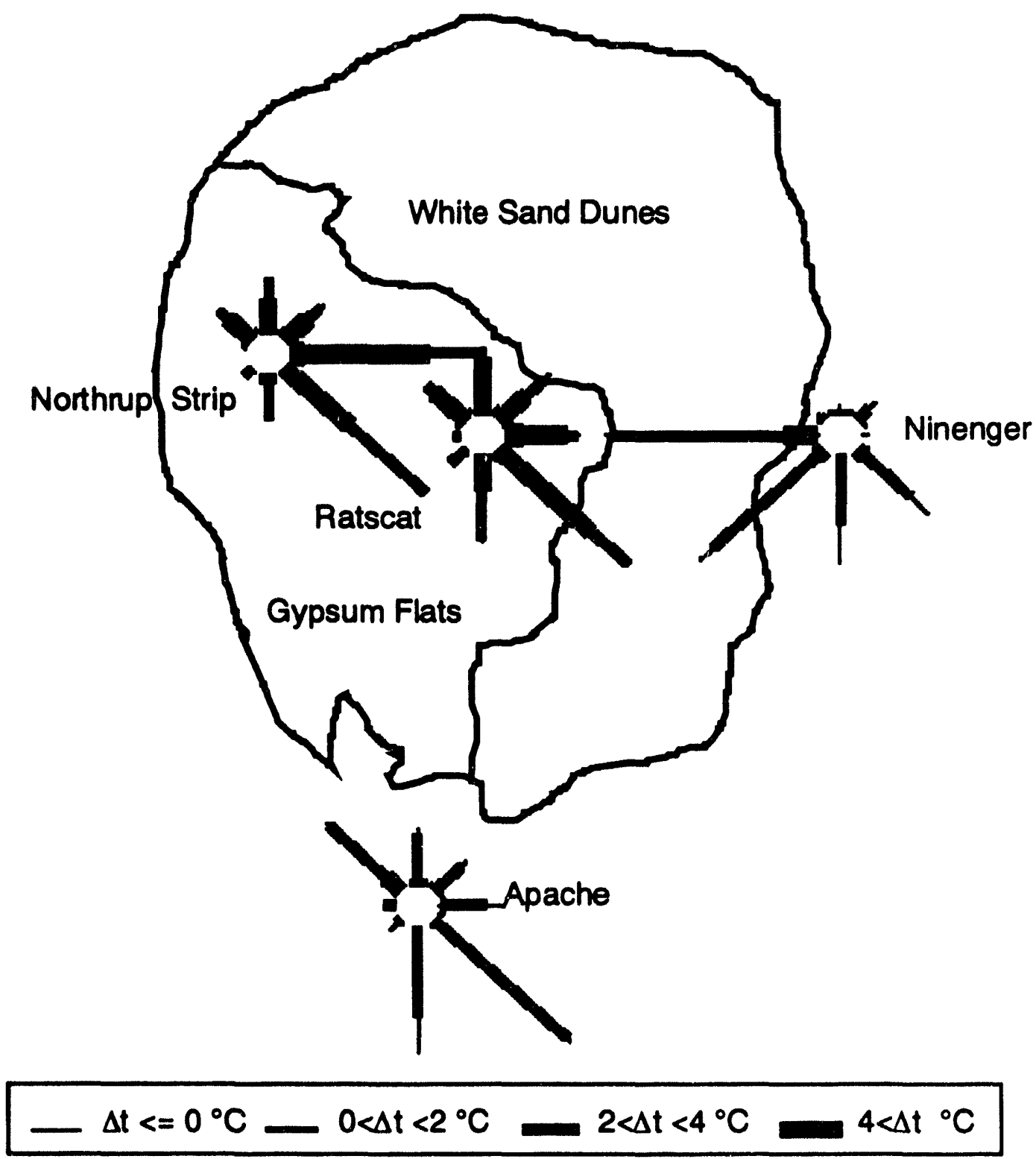


Figure 3b. Wind direction Frequency vs. $\Delta \mathrm{T}_{\mathbf{a}}$, Ninenger, Ratscat, Northrup Strip and Apache. June 1993. Plot is for non-rainy day time hourly data only. Directional axis represents wind direction vector. Vectors are pointing towards origin, which represents station location. As with a traditional wind rose, the length of the vector represents the frequency of occurrence for each wind direction. Width of each vector represents the magnitude of $\Delta T_{a}$. In this case the wind direction has been classified into 8 groups of $45^{\circ}$ each starting with $0^{\circ} \Delta \mathrm{T}_{\mathrm{a}}$. has been scaled into $\mathbf{4}$ groups as described in the legend below.

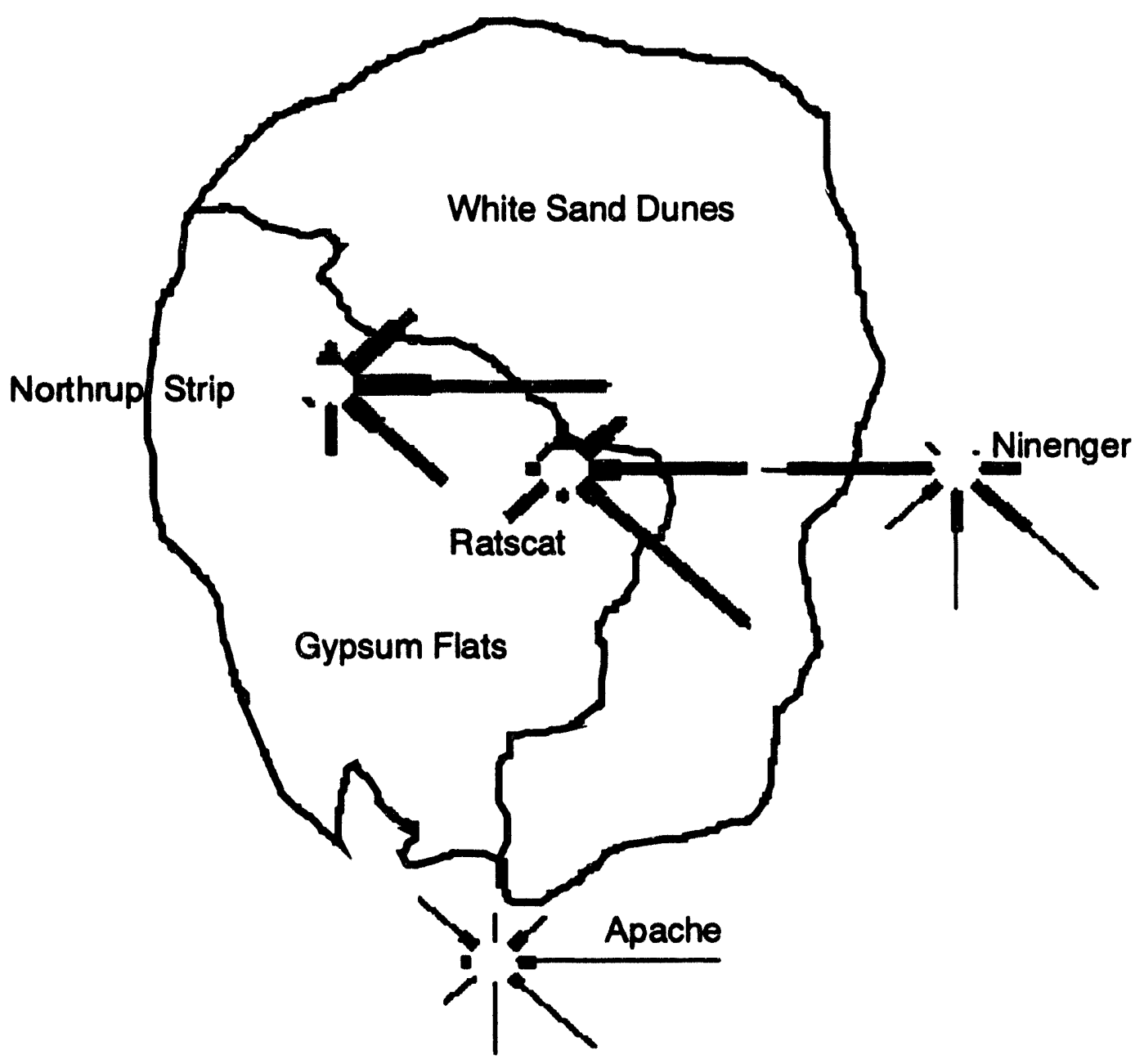
$\Delta t<=0^{\circ} \mathrm{C}$
$0<\Delta t<2{ }^{\circ} \mathrm{C}$
$2<\Delta t<4^{\circ} \mathrm{C}$
$4<\Delta t{ }^{\circ} \mathrm{C}$ 
Figure 4: Average $\Delta \mathrm{T}_{\mathrm{s}}$ by hour for $\left.\mathrm{A}\right)$ Ratscat and B) Northrup Strip. August 1992. All rain days have been omitted. Soil temperature is measured at $\sim 1-2 \mathrm{~cm}$ Northrup Strip may reach higher $\Delta \mathrm{T}_{\mathrm{s}}$ due to surface or sub-surface moisture. Average relative humidity, however, for Northrup Strip is less than that of Ratscat for the month of August.

A) Ratscat 1992

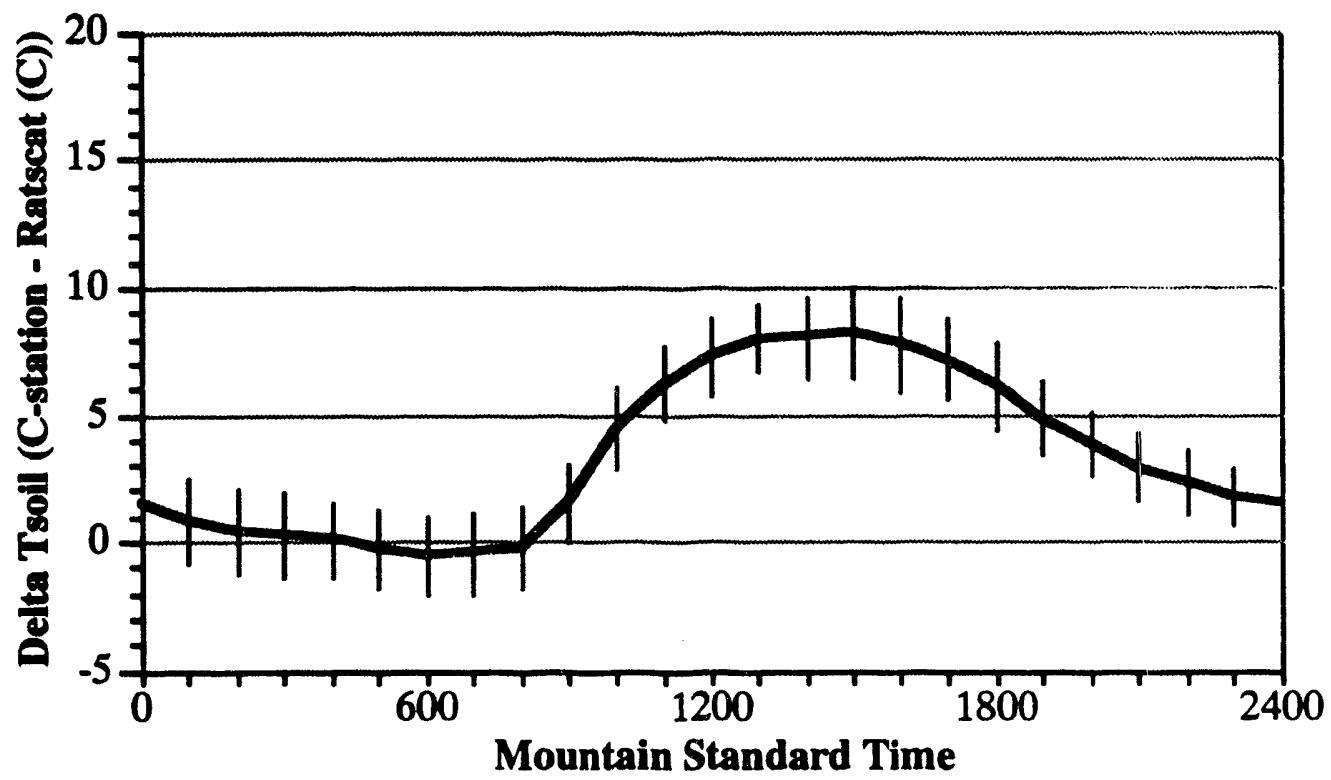

B) Northrup Strip 1992

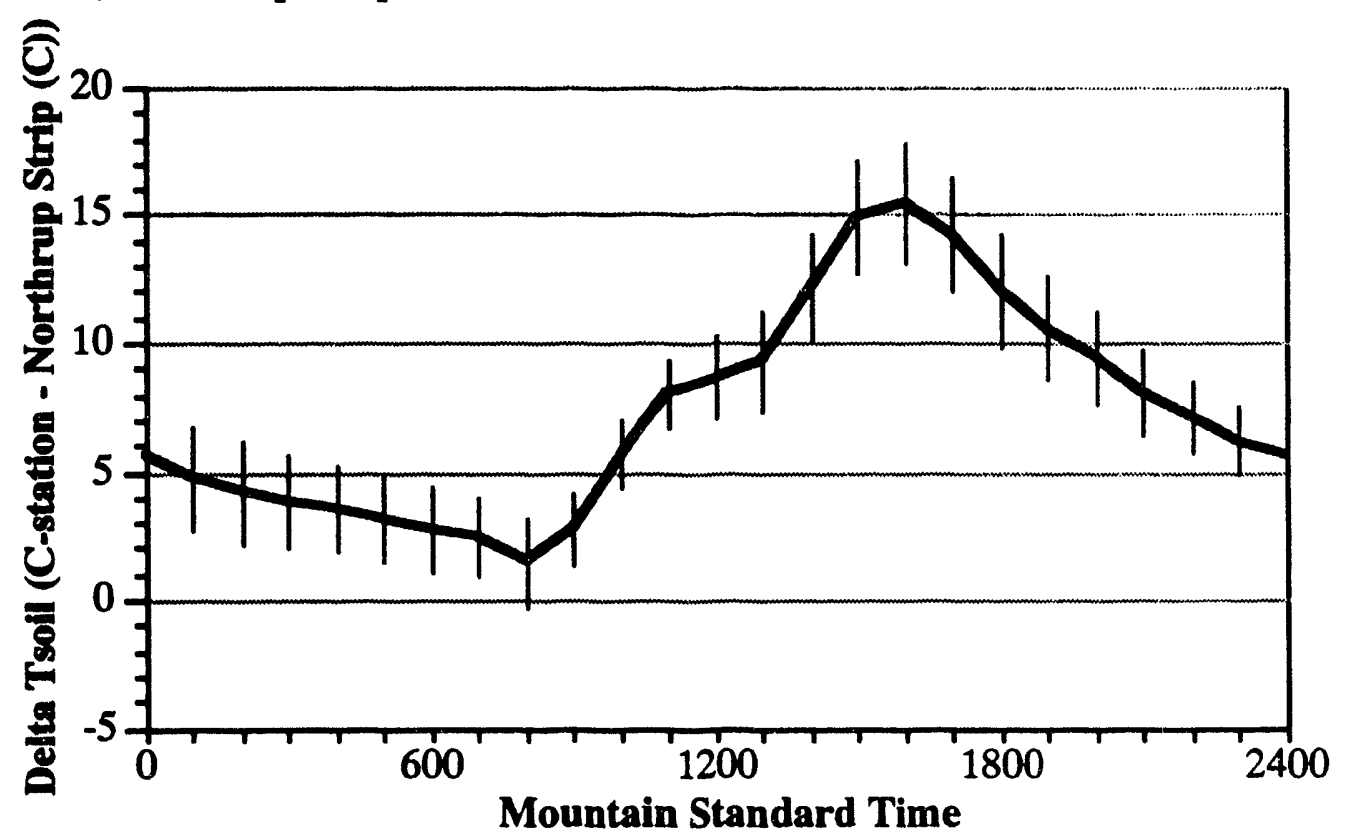


Table 3. Average $\Delta$ Tsoil for non-rainy days in August 1992. Averages are computed from 24 hours of data for non-rainy days only. Average daily peak difference is the difference of the daily maximums at $\mathrm{C}$-Station and Ratscat. Average daily maximum is the daily maximum difference. The difference in these two columns suggests that maximum $T_{S}$ and maximum $\Delta T_{s}$ do not occur simultaneously. Number of observations is 312 .

\begin{tabular}{|c|c|c|c|c|c|c|}
\hline $\begin{array}{l}\text { Station } \\
\text { Name }\end{array}$ & $\begin{array}{c}\text { Average } \\
\mathrm{T}_{\mathbf{s}} \text { ('C) }\end{array}$ & $\begin{array}{c}\text { Average } \\
\Delta \mathrm{T}_{\mathbf{S}}\left({ }^{\circ} \mathrm{C}\right) \\
\text { (Tcst-Tsoil) }\end{array}$ & $\begin{array}{c}\text { Standard } \\
\text { deviation } \\
\sigma\left({ }^{\circ} \mathrm{C}\right)\end{array}$ & $\begin{array}{c}\text { Maximum } \\
\Delta \mathrm{T}_{S}\left({ }^{\circ} \mathrm{C}\right)\end{array}$ & $\begin{array}{c}\text { Average daily peak } \\
\text { difference } \\
\left.\text { (maxT }_{\text {s-cst-max }} \mathbf{T}_{\mathbf{s}}\right) \\
(\mathbf{C})\end{array}$ & $\begin{array}{c}\begin{array}{c}\text { Average } \\
\text { daily } \\
\text { maximum }\end{array} \\
\Delta \mathrm{T}_{\mathrm{S}}\left({ }^{\circ} \mathrm{C}\right)\end{array}$ \\
\hline Apache & 31.48 & 0.74 & 3.15 & 6.67 & -1.45 & 3.76 \\
\hline C-Station & 32.22 & -...-..--.-... & ............ & -..--..-. & י-ניגו- & - \\
\hline Ninenger & 29.36 & 2.86 & 2.38 & 12.23 & 5.86 & 6.24 \\
\hline $\begin{array}{l}\text { Northrup } \\
\text { Strip }\end{array}$ & 24.86 & 7.36 & 4.46 & 18.35 & 13.26 & 15.52 \\
\hline Ratscat & 28.80 & 3.43 & 3.46 & 11.12 & 7.83 & 8.55 \\
\hline
\end{tabular}

Soil temperatures, because of the soil's thermal mass, exhibit thermal inertia, and will show a significant lag from solar radiation. We have no information on the soil properties, therefore we must determine this response lag time through statistics. Figure 5 shows soil temperature as a function of solar radiation. The figure shows clearly that C-Station has higher soil temperatures than Ratscat and Northrup Strip, given the same solar radiation. In this figure, solar radiation is lagged three hours, in order to remove the hysteresis which results from the expected lag time in soil temperature due to the downward heat flux through the soil. The lag time was determined by evaluating the error of the regression line selecting for the best statistics $\left(R^{2}\right.$ and the significance of the regressions).

Considering air temperatures, relative humidity, and solar radiation data are similar for all three stations, we can conclude from the figure that these differences in soil temperature are a direct result of differences in albedo. Note that regression lines for Ratscat and Northrup Strip have different slopes. The regression Results are provided below in Table 4. Although the error for these regressions is significant, the regressions reflect lower soil temperatures at Northrup 
Strip. This implies there is an effectively higher albedo at Northrup Strip than at Ratscat. As stated earlier, this may be due to surface moisture. However, since we have no measured data on surface moisture or its effect on albedo, we cannot determine the cause at this time.

Table 4. Regression Coefincients for Soil Temperature as a function of lagged Solar Radiation

\begin{tabular}{|cccc|}
\hline & $\mathbf{R}^{2}$ & Slope & Intercept \\
\hline Ratscat & 0.35 & 0.0082 & 26.97 \\
Northrup Strip & 0.32 & 0.0053 & 23.86 \\
C-Station & 0.45 & 0.013 & 30.65 \\
\hline
\end{tabular}


Figure 5. Soil Temperature as a function of Solar Radiation at Ratscat, Northrup Strip, and C-Station. Hourly data. Solar radiation is lagged three hours in order to remove hysteresis. All rainy days have been removed from the data set. The top line represents a regression line for C-Station, middle line represents regression line for Ratscat, and bottom line represents a regression line for Northrup Strip.

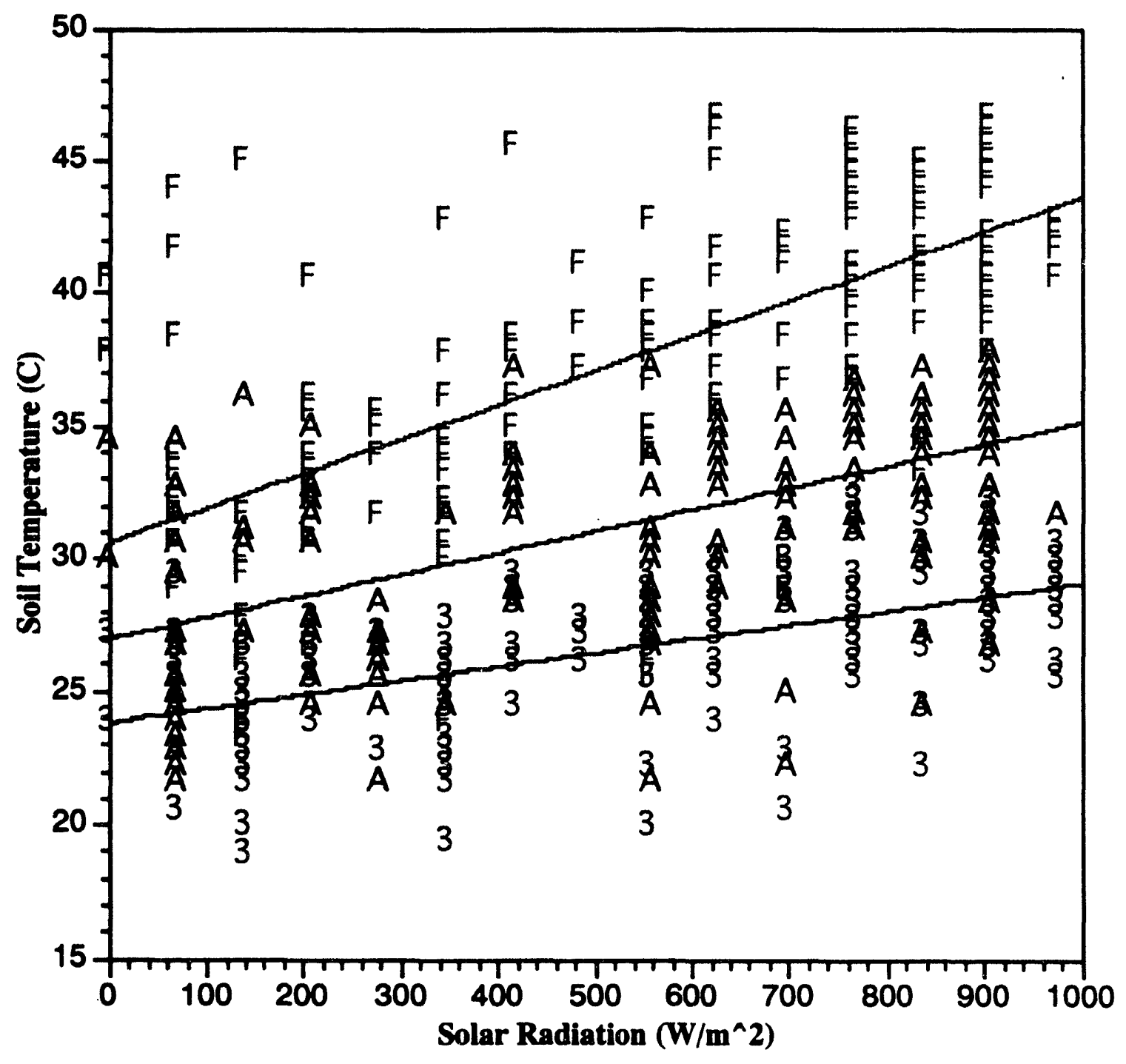
A Ratscat
3 Northrup Strip
F C-Station 


\subsection{Diurnal Patterns of Air and Soil Temperature}

Figure 6 shows average diurnal patterns for solar radiation, soil temperatures and air temperatures for August 1992. This figure clearly shows how air and soil temperatures at Ratscat remained cooler than at C-Station. As discussed above, both air and soil temperatures lag solar radiation by three to four hours. Because the surface has a tendency to warm the air, we would expect that air temperature will lag surface temperature. There will be some lag between surface and soil temperatures, but we do not expect it to be significant. The reason soil temperature lags air temperature by four hours cannot be determined at this time.

This figure demonstrates that air and soil temperatures are in phase. On some days, peak soil temperature precedes peak air temperature by up to one hour. This occasional lag time may be due to the difference between the albedo of the dunes and the that of the flats. Cooler air may come from the prevailing wind direction (south east) over the dunes and offset the peak air temperature, while the peak soil temperature remains unaffected. If this were the case we might expect to see peak temperatures at Ratscat delayed from those of C-Station due to its high albedo. Again this is not the case.

These anomalies may be due to the depth of the soil temperature probe, or instrumentation errors. We cannot determine any strong statistical relationship between soil temperature and air temperatures. There appears to be two different but statistically weak correlations for the afternoon period and the morning. The lack of correlation may be due to the covariance of both air and soil temperature. However, this lack of relationship may also be due to physical factors. Air temperature at any given station is probably not determined by the surface temperatures directly below, but by the surface characteristics a few meters or kilometers upwind, as well as many other atmospheric factors. In other words, air temperature may to be considered a global variable and are not necessarily linked to the specific geographic location of measurement. Surface temperature may be a considered a local variable, and can be directly associated with the location of measurement. 
Figure 6. Hourly Average Solar Radiation, Air and Soil Temperature at Ratscat and C-Station. August 1992. Non-rainy, Non-cloudy days only. Air and soil temperature peak simultaneously at Ratscat, however, soil temperatures lag air temperature by one hour at CStation. Peak soil temperatures at both stations lag solar noon by four hours. This is a result of the thermal mass of the soil. Solar radiation is not symmetrical around solar noon due to averaging and some presence of afternoon cloud cover in the data.
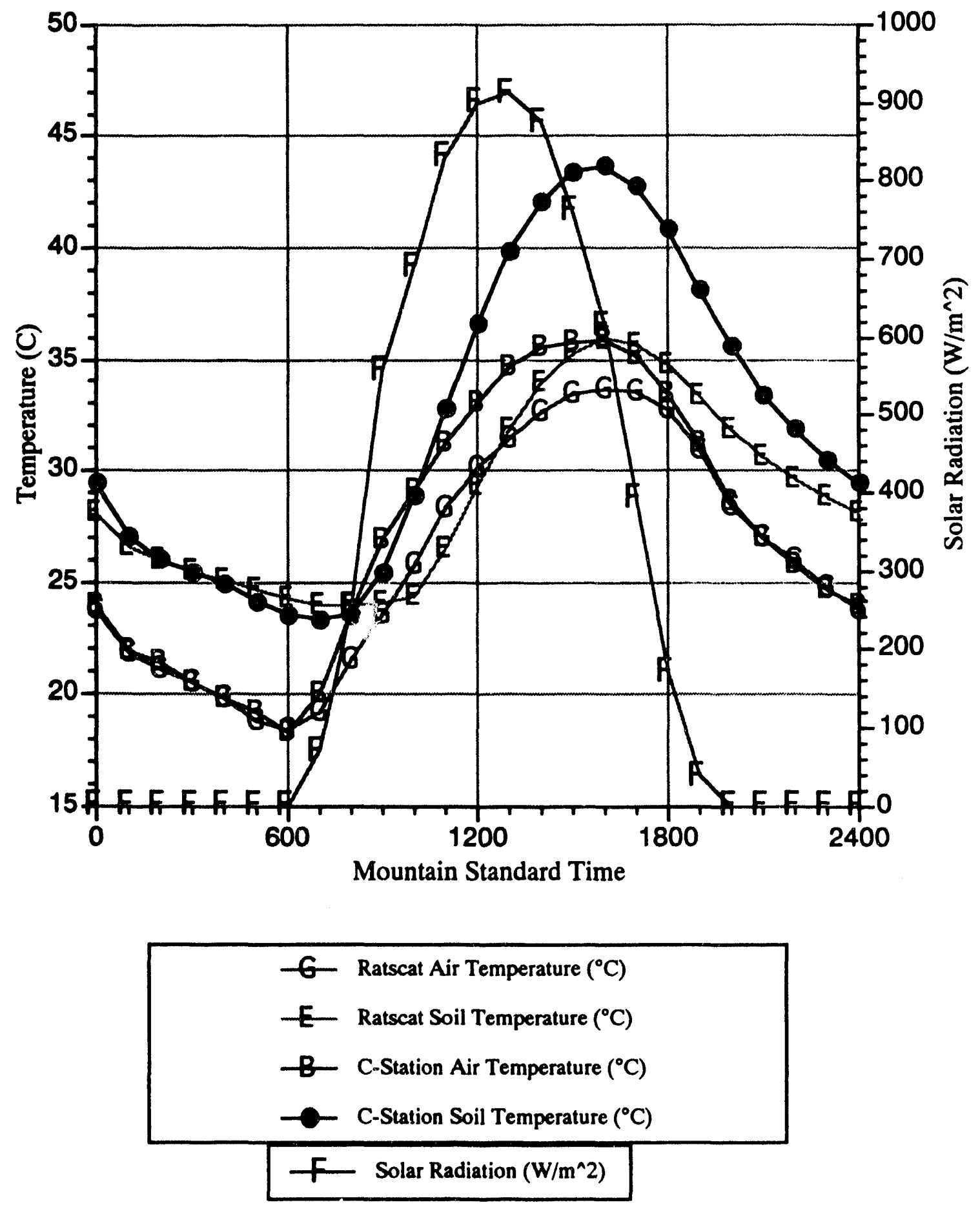


\section{SUMMARY AND CONCLUSION}

Analysis of the data has shown that the temperature depression within White Sands is between $1-3{ }^{\circ} \mathrm{C}$. Peak $\Delta \mathrm{T}_{\mathrm{a}}$ occurs in the morning hours, before any convective instability dilutes the effects of surface temperature on air temperature. This temperature depression is mainly observed within the White Sands area, although, on some occasions the temperature depression extends outside the White Sands boundary. Wind direction is observed to have some impact on this temperature depression and its effects on stations adjacent to White Sands. However, any dependence on wind speed cannot be identified at this time. Soil temperature data from August 1992 are consistent with our expectation of reduced surface temperatures within the dunes. But these data cannot be extrapolated to any functional relationship with air temperature. It appears that while soil temperature may be a local variable, air temperature may be a global variable for the entire White Sands basin. Advection, and possibly convection are identified to be the main factors diluting the effect of White Sands' high albedo surface on near surface air temperatures.

The data provided here, while of use in making initial estimates, does not contain the necessary detail to identify the determining factors that control the local effects of albedo on the near-surface air temperature. The random location of stations presents another difficulty for analysis, as does the occasional but unrecorded presence of surface moisture. Without any information on soil or surface moisture its impact on albedo and air temperature cannot be addressed.

In the future, several new variables would be helpful for this type of research: soil moisture, vertical wind speed and surface temperature. It would be preferable to collect data in June and possibly May, before the heavy rains begin. Installing several weather stations deeper within the dunes in a line along the prevailing wind direction would provide more information regarding the possible effects of wind speed on air temperature depression within the dunes. Satellite data may prove effective for obtaining surface temperatures and possible surface albedo. These data could be used in conjunction with surface weather stations to provide modeling input. 
Once the surface energy balance can be modeled, a more in-depth understanding of basin scale influences on these data may be possible.

\section{REFERENCES}

Akbari, H., Bretz, S. E., Hanford, J. W., Kurn, D. M., Fishman, B. L., \& Taha, H. G. (1993). Monitoring Peak Power and Cooling Energy Savings of Shade Trees and White Surfaces in the Sacramento Municipal Utility District (SMUD) Service Area: Data Analysis, Simulations, and Results (Final Report No. 34411). Lawrence Berkeley Laboratory.

Chapman, A. J. (1987). Fundamentals of Heat Transfer. New York: Macmillan Publishing.

Dodge, N. (1971). The Natural History Story of White Sands National Monument. Southwest Parks and Monuments Association.

Oke, T. R. (1982). The energetic basis of the urban heat island. Quarterly Journal of the Royal Meteorological Society, 108(455), 1 - 24.

Oke, T. R. (1987). Boundary Layer Climates ( 2 ed.). London: Methuen and Co.

Oke, T. R., Roth, M., \& Emery, W. J. (1989). Satellite-Derived Urban Heat Islands from Three Coastal Cities and the Utilization of Such Data in Urban Climatology. International Journal of Remote Sensing, 10(11), 1699-1720.

Sailor, D. J. (1993). Role of Surface Characteristics in Urban Meteorology and Air Quality. Phd, University of California, Lawrence Berkeley Laboratory.

Smith, G. R. (1984). Surface Soil Moisture Measurements of the White Sands, New Mexico (tech memo No. NESDIS 7). Satellite Experiment Laboratory, NESDIS/NOAA, U.S. Dept. of Commerce.

Smith, G. R., Levin, R. H., \& Knoll, J. S. (1985). An Atlas of High Altitude Aircraft Measured Radiance of White Sands, New Mexico, in the 450-1050 nm Band (tech report No. NESDIS 20). NOAA/NESDIS, U.S. Dept. of Commerce.

Taha, H., Sailor, D., \& Akbari, H. (1992). High-Albedo Materials for Reducing Building Cooling Energy Use No. No. 31721). Lawrence Berkeley Laboratory. 
Taha, H. G. (1993). On Measuring the Albedo of Small Surfaces in the Field, A technical note to be submitted to Theoretical and Applied Climatology (Draft Report in Progress No. Lawrence Berkeley Laboratory.

Walraven, R. L., \& Coulson, K. L. (1972). Measurements of the Light Properties of Gypsum Sand (Contributions in Atmospheric Science, no. 7 No. U. S. Department of Commerce Contract No. 2-3711). Department of Agricultural Engineering, University of California, Davis. 

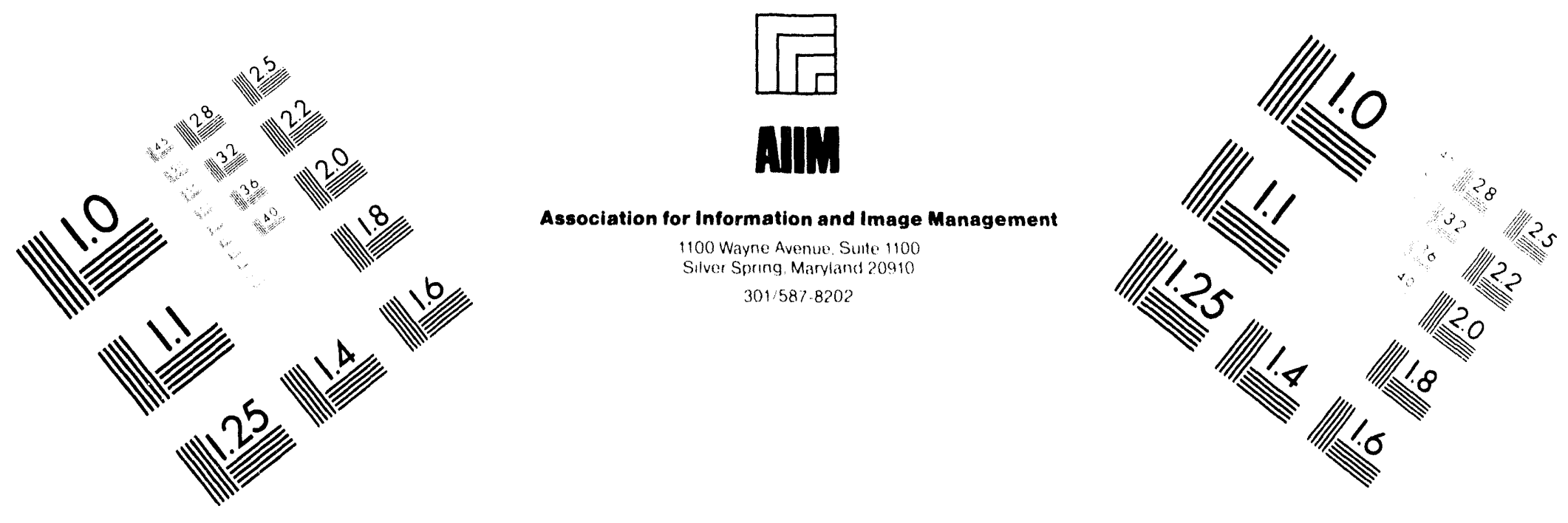

\section{Centimeter}

$\begin{array}{llllllllllllllll}1 & 2 & 3 & 4 & 5 & 6 & 7 & 8 & 9 & 10 & 11 & 12 & 13 & 14 & 15 & \mathrm{~mm}\end{array}$

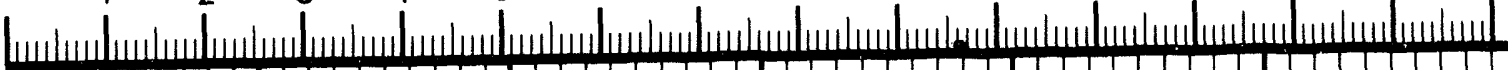
TITाTा Inches
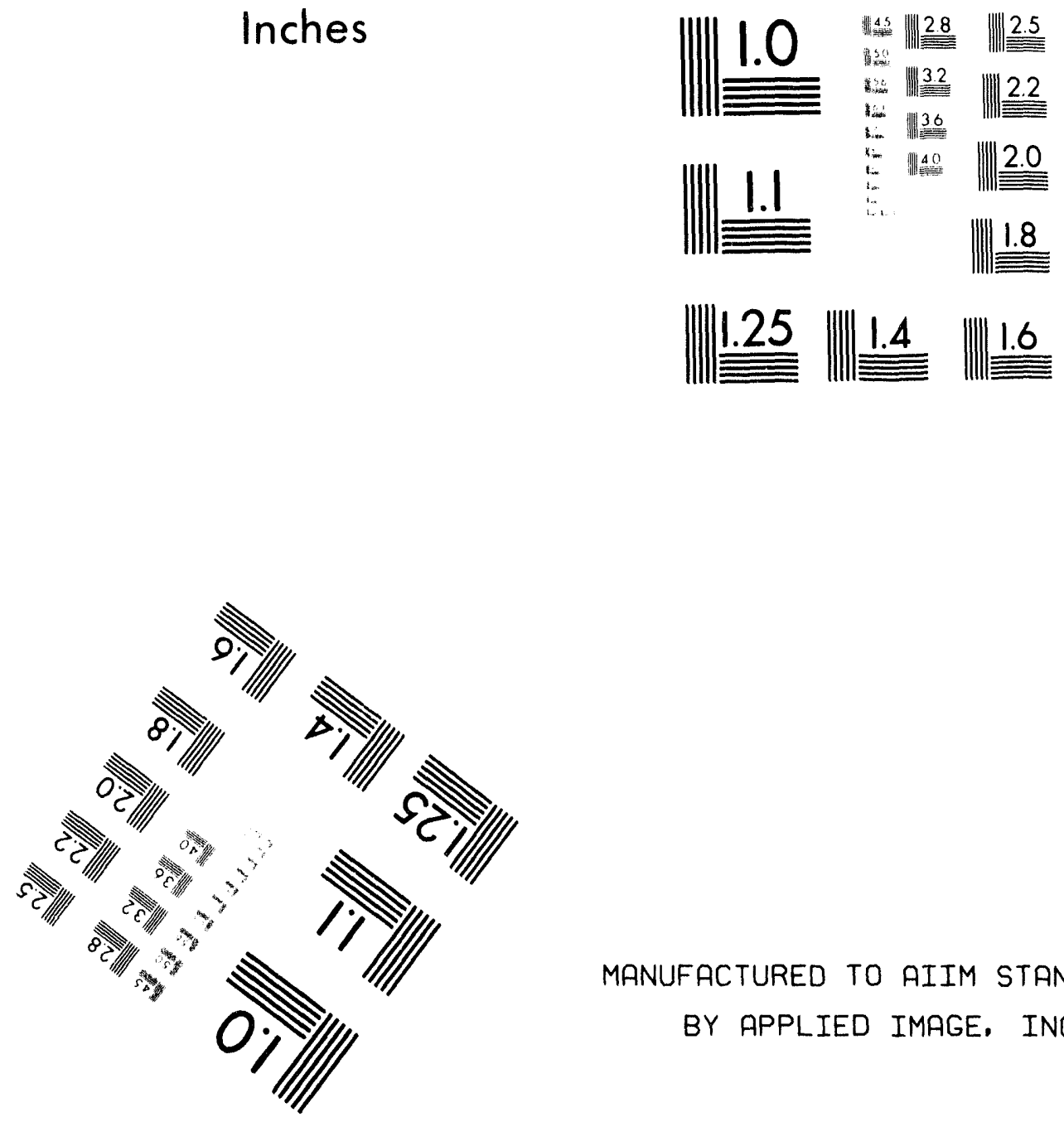

MANUFACTURED TO AIIM STANDARDS

BY APPLIED IMAGE, INC.

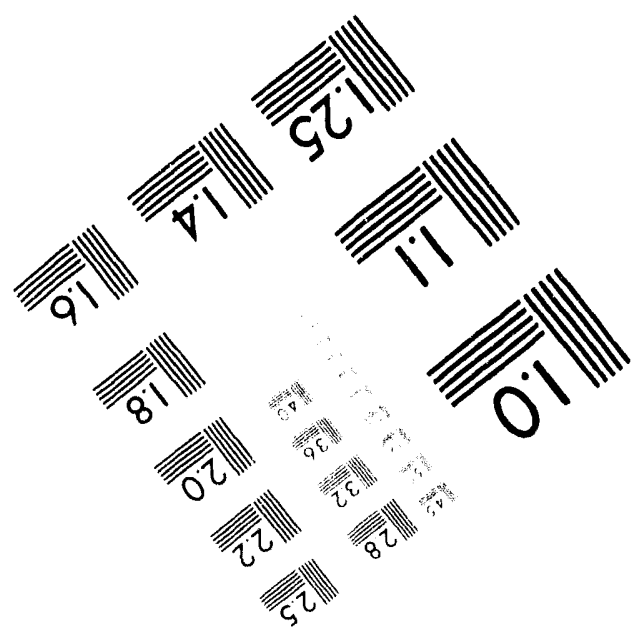




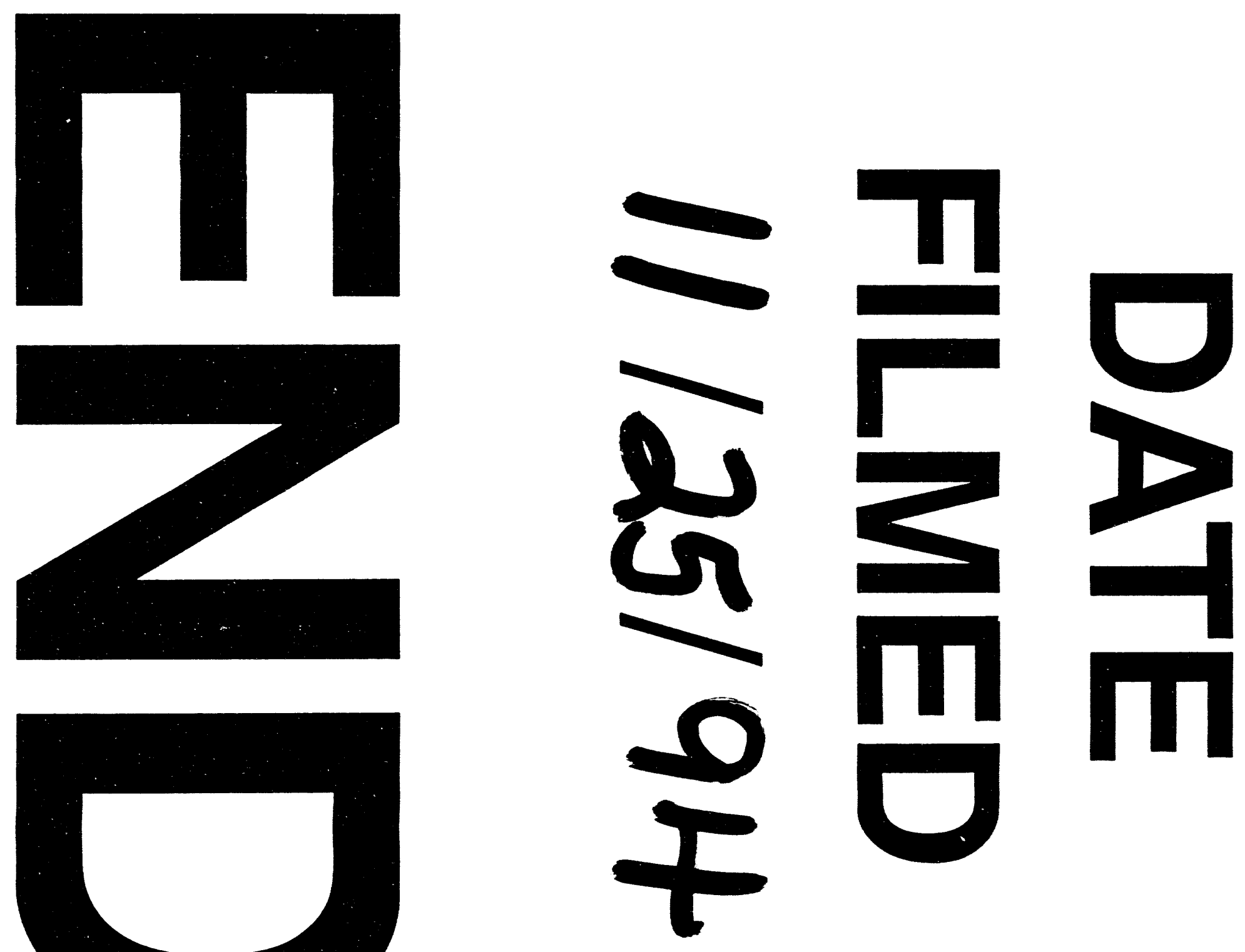